A Guiding Framework for Considering Touchscreens in Children under Two Natalia Kucirkova, BSc (Hons), MRes, $\mathrm{PhD}^{\mathrm{a}}$ and Barry Zuckerman $\mathrm{MD}^{\mathrm{b}}$

Affiliations: University College London, Institute of Education a , Department of Pediatrics, Boston Medical Center and Boston University School of Medicine ${ }^{b}$ Address correspondence to: Natalia Kucirkova, Department for Learning \& Leadership, Bedford Way 20, London WC1H 0AL, [n.kucirkova@ucl.ac.uk], 00447910594681 Keywords: technology, parenting, child development, infant, user-computer interface, computers, handheld, microcomputers, smartphone Abbreviations: AAP $=$ American Academy of Pediatrics; app $=$ application, $\mathrm{TV}=$ television. 
Parents, teachers, pediatricians and other child health professionals face the challenge of widespread $^{1}$, increasing $^{2}$ and multipurpose ${ }^{3}$ use of touchscreens. Even toddlers are accessing technologies such as tablets, smartphones, iTouch and other mobile devices with increasing frequency. Child use of this engaging technology is associated with diverse beliefs and practices on the part of parents, motivated by what is best for the child and by the difficulty of limiting touchscreen use ${ }^{4}$.

The American Academy of Pediatrics (AAP, 2016 ${ }^{5}$ ) concludes that there is insufficient evidence to suggest that the use of technology is beneficial for children under 18-24 months and recommends that screen media be discouraged for this age group. Toddler use of touchscreens has exploded nonetheless and child health professionals and educators require a more adequate research base to confidently communicate recommendations to parents. Yet, as with any innovative technology intervention, a key research challenge relates to building a longitudinal evidence base with a rapidly evolving hardware features and functionalities, necessitating repeated research studies.

This short narrative review builds on a recent summary of the field ${ }^{6}$ and broader recommendations concerning all screens and screen time more generally $y^{7,8}$ to propose a guiding framework concerning touchscreens and children aged under two years. The aim is to support health professionals, researchers, educators and advocates, in their discussions with parents about touchscreens' use with children under two years. There are four inter-related factors in this framework: research, content, context and developmental issues. There is no specific order to these four factors, and some are more related to each other than others, depending on the circumstances. We review the literature according to the four factors with the purpose of providing a clear view on the area of interest and at the same time, highlighting that the four 
issues constitute one framework that, as a whole, needs to guide future research, practice and thinking in this area.

\section{Research issues}

Longitudinal evidence is needed to establish the effects of early onset use of touchscreens. The research base for the current AAP recommendations pertains largely to television and CD-ROM whereas current concerns relate primarily to the use of interactive touchscreens. Another methodological issue relates to the inconsistent definition of interactivity associated with children's digital books accessible on touchscreens. Here, interactivity can relate to interactive areas within the book, that can be activated through touch (the so-called hotspots ${ }^{9}$ ), but also to the interactivity between the child and an adult. ${ }^{10}$ In addition, different research teams subsume different features under the broad umbrella term of interactivity ${ }^{11}$. While some researchers distinguish between interactivity and multimedia features ${ }^{12}$, others focus on more narrowly defined features of the child's interactive experience with digital books ${ }^{13}$. These features include customization of stories, direct manipulation of on-screen characters, augmented and virtual reality.

A more refined definition of interactivity is also needed in video-based learning and communication where attention gets activated through verbal and visual stimuli rather than textual prompts. Emerging data ${ }^{14}$ show that children under age 3 can learn new words (verbs), as well as respond in a reciprocal manner to learn novel patterns ${ }^{15}$, from socially interactive input from touchscreens (e.g. video chat). Online surveys ${ }^{16}$ show that parents often use video chat to establish and maintain relationship between their young children and remote parents and relatives. Given the often shared and social context of use, and communication-relevant 
experiences with touchscreens, some $\operatorname{argue}^{17}$ that such use of touchscreens should not count as part of children's screen time and be treated as a separate research category.

A final research issue, not included in most policy statements, is the need to promote a broader range of research methods including qualitative studies (such as ethnography, multimodal analysis), as well as research with ethnically and culturally diverse groups. These alternative research methods can provide theoretical extensions, lead to the development of alternative outcome measures, and help explain learning mechanisms. These research issues affect our understanding of how touchscreens influence children's development and their contribution needs to be considered in light of unique developmental factors germane to children under the age of two.

\section{Developmental factors}

In a recent online survey, 715 parents of 6- to 36-month-olds retrospectively reported the age of first touchscreen usage, walking, stacking blocks, and producing two-word utterances (i.e., the gross motor, fine motor and language milestones). ${ }^{18}$ The researchers concluded that the novel interactive characteristics of touchscreens could improve children's developmental skills such as fine motor control, hand/eye coordination and visual attention. Causal relations cannot be deduced from a retrospective parent survey and therefore, other empirical data, especially data that would be supplemented with observations and interviews with parents, are necessary for gauging the potential impact of touchscreens on the developmental capacities and needs of young children.

First, a developmental approach needs to consider the multipurpose role of touchscreens in infants' lives beyond learning and for situations of use where convenience is important. Some parents use mobile devices to calm or quiet ${ }^{19}$ or distract their infants and toddlers in situations 
such as airplane trips or medical procedures. Thus, touchscreens potentially affect children's lives in several distinct ways, including children's self-regulation skills and parents' regulation strategies.

Second, age-related guidance risks excluding children whose abilities do not follow typical developmental patterns. Although the AAP guidance refined the cut-off point from twoyear-olds to 18-24-month-olds, parents, as they already do with many other activities ${ }^{20}$ need to consider children's actual developmental skills and temperamental differences.

Third, developmental skills need to be addressed individually for potential benefit or negative association. Here, knowledge from well-established areas of research can be incorporated into current considerations. For example, for reaching and grasping skills, infants progress from accidental reach to more purposeful reach of objects that is not fine-tuned until about nine months ${ }^{21}$. Even after this milestone, it is only with 3D explorations that children's hand-eye-coordination and problem-solving skills can improve ${ }^{22}$. Thus, if a child has multiple objects at their disposal, touchscreens are unlikely to add value to obtaining this skill in infants. On the other hand, children's language and cognitive competencies start with parent verbal and gestural responsiveness to child's utterances and gestures, leading to turn taking ${ }^{23}$. This experience represents a shared intention to communicate and value each other - a critical step for children's social and emotional development ${ }^{24}$. Such experience could be extended and enriched with touchscreens' use around family photo-sharing, for example.

\section{Technology-related factors}

Different touchscreens come with different kinds of software programs and skills necessitating their use. The first factor to consider is the suitability of the device for the child. As the name reveals, touchscreens are manipulable by touch, which may give the impression that 
they are "intuitive" or easier to use than other technological devices. Icon-based navigation allows for independent exploration ${ }^{25}$, but there are also physical skills that a child needs to master when operating an adult device. An observation study ${ }^{26}$ of $14-22$ months in a UK nursery revealed that children needed to learn how to handle the weight of the tablet while developing finger dexterity and stability in order to use tablets effectively. Furthermore, mastery of skills required for a specific activity on a touchscreen (e.g., InnoTab 2 Baby, a tablet game developed specifically for infants) does not necessarily translate to other fine-motor skills not involving a tablet.

Another key novel factor of touchscreens is that they are multimedia, that is they converge several media into one device. While single-function technologies afford a limited number of activities, there are a number of positive possibilities with touchscreens. The best examples include a camera, which can be used for taking pictures, video-calls with a traveling parent or absent grandparents to maintain connection; parent-child mutual enjoyment of music and visuals. Each functionality has different features and usage and their convergence in one device can be beneficial or challenging. For functionalities comparable to non-digital alternatives (e.g., a digital drawing board, which can be used for letter tracing or coloring just like paper-based drawing board), parents, and those who advise them, have to reflect on their own media practices to determine the, added value, if any, of this technology, in specific circumstances to achieve specific goals (e.g., learning different skills, distraction, family enjoyment).

\section{Content-related factors}

Based on studies examining the effects of learning new words from video on 2D screens, ${ }^{27,28}$ we can deduce that young children can learn new words from touchscreens in some 
conditions: specifically, the apps must provide high-quality content and the child's learning must be effectively supported by an adult communicating with the child in real time. If content is designed to scaffold children's learning as it is the case with lab-based content, then 24-montholds can learn how to solve a puzzle or learn new words ${ }^{29}$. Several app curating websites (e.g., Common Sense Media, Children's Technology Review) evaluate the educational potential of apps based on theory-driven criteria ${ }^{30}$ or parents' feedback, and are a good resource for parents. Future research needs to examine the effects of specific content features on infants' learning, especially in terms of psychological and non-cognitive outcomes.

\section{Context-related factors}

Previous research has examined children's use of technology in labs, homes or kindergartens ${ }^{31}$. With touchscreens, however, the context of use has been widened to the socalled third spaces (e.g., journey from home to pre-school; long-haul flights and bus rides; grocery shopping and restaurants; waiting rooms). For the majority of young US children, there is a potentially ubiquitous third space presence of touchscreens during a day. Based on their values, available resources and pragmatic considerations, parents need to decide how to balance technological engagement versus human engagement during third space time. These are not mutually exclusive choices and it is clear that there are often short, disconnected three-way interactions between the parent, touchscreen and the child. This makes it difficult to estimate and recommend the overall time children should daily spend with touchscreens (cf AAP, 2016). Last but not least, for all children but especially for younger children, technology use is by and large managed by their parents/caregivers whose own use and views and attitudes, are crucial in mediating children's actual use of touchscreens at home $\mathrm{e}^{32,33}$. 


\section{Framework summary}

Based on a conceptual synthesis of the latest evidence on touchscreens and the youngest children with age two and under as a flexible age guideline, this review led to a guiding framework to support future thinking and activities of researchers and practitioners and appraise emerging research, about the role touchscreens might play in children's development. The complex nature of potential effects of touchscreens on young children can be broken down into developmental, technology-, content- and context-related considerations. It is important to have a discussion with parents about whether touchscreens and their multipurpose use are necessary for their child to achieve certain skills and how much their child's use, let alone their own use, displaces interactions with people. For technology-related factors, the suitability of functionality and quality of each activity enabled by a specific device and specific program downloaded on this device, needs to be considered. The quality of the content and the overall suitability of the device for the child, are important. For context-related factors, the third space use of touchscreens by children under two is already occurring, but merits further evaluation. Child health professionals can communicate this information when asked about the validity of a causal relationship between scientific evidence concerning touchscreens and child effects. Child professionals and parents can jointly evaluate how the home environment influences children's use of these technologies and how the family dynamics and parents' own technology practices impact on their children.

Regardless of what the eventual evidence shows about the value of touchscreens for children under two, it is important that children's physicians and others keep a socio-empirical approach towards the interpretation of this evidence and their recommendations for individual families. The framework outlined here can help guide this process. 


\section{Acknowledgments:}

The authors thank Jane O'Neil PhD, Michael Levine PhD, Amber Marie Levinson PhD and Jenny Radesky MD for their helpful comments on an earlier version of this manuscript.

Conflicts of Interest: The authors have no relevant conflicts of interest to disclose. 


\section{References}

1. Kabali HK, Irigoyen MM, Nunez-Davis R, et al. Exposure and use of mobile media devices by young children. Pediatrics. 2015. Published online November 2, 2015. doi:

10.1542/peds.2015-2151

2. Common Sense Media \& Rideout V. Zero to eight: Children's media use in America.

Common Sense Media; 2011; 2013. [Available at:

https://www.commonsensemedia.org/research/zero-to-eight-childrens-media-use-in-america.

Accessed March 4, 2016]

3. Kucirkova, N., \& Littleton, K. The digital reading habits of children. 2016; London: Book Trust.

4. Radesky JS, Kistin C, Eisenberg S, Gross J, Block G, Zuckerman B, Silverstein M. Parent perspectives on their mobile technology use: the excitement and exhaustion of parenting while connected. Journal of Developmental \& Behavioral Pediatrics. 2016; 37(9):694-701.

5. American Academy of Pediatrics Council on Communication and Media: Hill D, Ameenuddin N, Chassiakos YL, Cross C, Hutchinson J, Levine A, Boyd R, Mendelson R, Moreno M, Swanson WS. Media and Young Minds. Media and Young Minds; 2016. Pediatrics, e20162591.

6. Radesky, J. S., Schumacher, J., \& Zuckerman, B. Mobile and interactive media use by young children: the good, the bad, and the unknown. Pediatrics. 2015; 135(1): 1-3.

7. Lerner, C., \& Barr, R. Setting the record straight - Research-based guidelines for screen use for children under 3 years old. Washington, DC: Zero to Three, 2014.

8. Radesky, J. S., \& Christakis, D. A. Increased Screen Time: Implications for Early Childhood Development and Behavior. Pediatric Clinics of North America. 2016; 63(5), 827-839. 
9. Takacs, Z. K., Swart, E. K., \& Bus, A. G. (2015). Benefits and pitfalls of multimedia and interactive features in technology-enhanced storybooks a meta-analysis. Review of educational research, 0034654314566989.

10. Sharkins, K. A., Newton, A. B., Albaiz, N. E. A., \& Ernest, J. M. (2016). Preschool children's exposure to media, technology, and screen time: Perspectives of caregivers from three early childcare settings. Early Childhood Education Journal, 44(5), 437-444.

11. Stichnothe, H. (2014). Engineering stories? A narratological approach to children's book apps. BLFT-Nordic Journal of ChildLit Aesthetics, 5.

12. Bus, A. G., Takacs, Z. K., \& Kegel, C. A. (2015). Affordances and limitations of electronic storybooks for young children's emergent literacy. Developmental Review, 35, 79-97.

13. Zipke, M. Preschoolers explore interactive storybook apps: The effect on word recognition and story comprehension. Education and Information Technologies, 2016; 1-18.

14. Roseberry, S., Hirsh-Pasek, K., \& Golinkoff, R. M. Skype me! Socially contingent interactions help toddlers learn language. Child Development. 2014; 85(3): 956-970.

15. Myers, L. J., LeWitt, R. B., Gallo, R. E., \& Maselli, N. M. Baby FaceTime: can toddlers learn from online video chat?. Developmental Science.2016; Published online before print. DOI: $10.1111 /$ desc. 1243

16. McClure, E. R., Chentsova-Dutton, Y. E., Barr, R. F., Holochwost, S. J., \& Parrott, W. G. "Facetime doesn't count": Video chat as an exception to media restrictions for infants and toddlers. International Journal of Child-Computer Interaction. 2015; 6: 1-6.

17. McClure, E. R., \& Barr, R. F. Building Family Relationships from a Distance: The role of communication technology. In: R.F. Barr, D. Linebarger (Eds.), Media Exposure During 
Infancy and Early Childhood: The Effect of Content and Context on Learning and Development. 2016; Springer.

18. Bedford, R., de Urabain, I. R. S., Cheung, C. H., Karmiloff-Smith, A., \& Smith, T. J. Toddlers' Fine Motor Milestone Achievement Is Associated with Early Touchscreen Scrolling. Frontiers in Psychology. 2016: 7, online.

19. Radesky JS, Peacock-Chambers E., Zuckerman B, \& Silverstein M. Use of Mobile Technology to Calm Upset Children: Associations With Social-Emotional Development. JAMA pediatrics. 2016; 170(4), 397-399.

20. Sanson, A., Hemphill, S. A., \& Smart. Connections between temperament and social development: A review. Social Development. 2004; 13(1), 142-170.

21. Woodward, A. L. Infants selectively encode the goal object of an actor's reach. Cognition. 1998; 69(1), 1-34.

22. Montgomery, P., \& Connolly, B. H. Clinical applications for motor control. 2003; Slack Incorporated.

23. Bates, E. The emergence of symbols: Cognition and communication in infancy. 2014; Academic Press.

24. Tomasello, M.Origins of human communication. 2010; MIT press.

25. Geist, E.A. A Qualitative Examination of Two Year-Olds Interaction With Tablet Based Interactive Technology. Journal of Instructional Psychology. 2012; 39 (1):26-35.

26. Merchant G, Keep taking the tablets: iPads, story apps and early literacy. Australian Journal of Language and Literacy. 2015; 38(1): 3-11.

27. Richert, R. A., Robb, M. B., Fender, J. G., \& Wartella, E. Word learning from baby videos. Archives of pediatrics \& adolescent medicine. 2010; 164(5): 432-437. 
28. Barr, R. Memory constraints on infant learning from picture books, television, and touchscreens. Child Development Perspectives. 2013; 7(4): 205-210.

29. Kirkorian, H. L., Choi, K., \& Pempek, T. A. (2016) 'Toddlers' word learning from contingent and noncontingent video on touch screens', Child Development, 87(2): 405-413.

30. Kucirkova, N., Littleton, K., \& Cremin, T. Young children's reading for pleasure with digital books: six key facets of engagement. Cambridge Journal of Education. 2016; 1-18.

31. Hipp D, Gerhardstein P, Zimmermann L, Moser A, Taylor G, Barr R. The dimensional divide: Learning from TV and touchscreens during early childhood. In Barr, R \& Linebarger DN (eds) Media Exposure During Infancy and Early Childhood. 2017 (pp. 33-54). Springer International Publishing.

32. Radesky JS, Eisenberg S, Kistin et al. Overstimulated consumers or next-generation learners? Parent tensions about child mobile technology use. Annals of Family Medicine. 2016; 14(6), $503-508$. 